\title{
Announcement
}

\section{IRFIS 5: Call for papers}

The Fifth International Research Forum in Information Science (IRFIS 5): "Representation and Exchange of Knowledge as a Basis of Information, Processes", hosted by the German Society for Documentation, Section for Information Science, will be held at the Hotel Molkenkur, Klingenteichstrasse 69, in Heidelberg, Federal Republic of Germany, September 5-7, 1983.

In particular, the following aspects of information and communication science will be covered:

- methods of knowledge representation,

- new mechanisms for the transfer and use of knowledge,

- advances in human-machine interaction.

Researchers with experience in these-and related-areas are cordially invited to submit proposals for papers they would like to present. *

Objectives of IRFIS 5 are:

- to develop ideas about a coordinated European research program in information science;

- to intensify international exchange of experience in information science, and to improve international cooperation in certain research topics.

Responses to this call for papers as well as any further requests regarding IRFIS 5 should be addressed to: Dr. Hans Dietschmann, Coordinator, IRFIS 5, Gesellschaft für Information und Dokumentation, Lyonerstrasse 44-48, D-6000 Frankfurt/Main 71, Federal Republic of Germany.

An application form for participation appears on the following page. (Please photocopy if required.)

\footnotetext{
* Restricted funds are available to reimburse travel expenses for speakers.
} 
Application Form (deadline for applications: 31 March, 1983)

Name:

Position:

Organization:

Address: 